\title{
On radical transformation
}

\author{
Bidisha
}

There is an assumption that just because time is passing, things are getting better. Yet societies can regress as well as advance. They can repeat mistakes, refuse to learn, slip back into old sins. We are currently living through one such time of regression, but Creativity and Resistance in a Hostile World seeks to break the momentum of this backward slide with its proactive, radically honest confrontations. Each chapter takes the way we live now as its starting point and brings it into touch with strategies of creativity, activism and liberation. It takes inspiration globally, from Palestinian resistance through the art of film to overcoming racial inequality in the British mainstream media.

The list of twenty-first-century horrors motivating these resistance movements is long. Machismo and misogyny, racist violence, white supremacy, dictatorial and authoritarian leaders, militarisation and surveillance, xenophobia, philistinism, insularity and jingoism are features of many countries globally - including those that had once trumpeted democratic and inclusive values. We talk about 'troubling times'. Well: they're here. Within such a context, artists and workers across the culture and creative sectors fight to reflect, respond and resist. This book is an active confrontation, a tabling of solutions, an intervention, an engagement and a challenge. The powerful opening chapter, 'Radical openness in a 


\section{On radical transformation}

hostile world', by Churnjeet Mahn, Sarita Malik, Michael Pierse, and Ben Rogaly, provides a valuable overview both of the deep political roots of the current global order and of the manifold ways, from grime music to street theatre, that modes of oppression are questioned, critiqued and challenged. They also remind us of the usefulness of Black feminist and antiracist writer bell hooks' notion of radical openness, which enables links to be made across different systems of oppression and different (creative) expressions of resistance.

It is undeniable, however, that Creative Interruptions has been created by the very people who appear to be embedded within hierarchies, institutions and structures that enact, replicate and amplify the very inequalities we are seeking to dismantle. The second chapter, "Lived theory": the complexities of radical openness in collaborative research', considers the importance of embodying the intentions in the means, without glossing over any persistent hypocrisies, contradictions and complications. Above all, it highlights the importance of self-awareness in the artistic resistanceand-liberation project. Or, to put it in millennial terms, checking one's privilege. Alternatively, to put it in radical 1970s feminist and civil rights terms, walking the talk.

Creative Interruptions has emerged at a time when it appears, on the surface, that issues of equality and representation are front and centre in mainstream media discourse. Every so often, major institutions like the $\mathrm{BBC}$ release, fret over and pledge to do better 'on' women or 'on' race. Yet, despite their speaking the language of liberation, real action and change are painfully slow to happen, and clearly the existing methods for achieving transformation have not worked. In the third chapter, titled 'Creative anti-racisms: screen and digital labour as resistance', the authors explore new ways of getting around hackneyed promises, the same old conversations around 'diversity and inclusion', and replacing good (or at least nicely stated) intentions and institutional barriers with a new approach. This is required so that the next generation of media users, media workers and media commentators do not have to butt up against the same disheartening facts or mollifying, glib, ineffective responses. 


\section{On radical transformation}

The current Brexit era of aggressive and self-righteous insularity, of a defiant defence of monoglot mono-culturalism, requires aggressive correction. The arts, culture and media must resist this narrowing of horizons, admit their own limitations and perform a spectacular turnaround, recognising the voices and faces they have ignored for too long. It is time for white authority figures to stop talking and start listening, stop defending and start changing their behaviour and humbly cede floorspace to stories, images and works from non-white, diaspora, migratory and minority creators.

In the fourth chapter, 'Workers: creative resistance to racial capitalism within and beyond the workplace', Ben Rogaly takes this further, applying a race-aware analysis to the very underpinning of capitalism, careerism, organisations and institutions. For so many workers far from the outward glitz of the media and creative industries, to raise problems of discrimination within the workplace is to become the problem within the workplace; to try talking about race (even when invited to under the guise of 'diversity and inclusion' initiatives) is so often to re-experience racist interactions, to be disbelieved, gaslighted and dismissed. Clearly, the old ways aren't working.

That is where art comes in. The old teasing questions, 'But what is art? What makes something art?' are here a point of opportunity. The very formlessness of the concept and the slipperiness of its definition make it resistant to co-option by the institutions, regimes or hierarchies which perpetuate inequality. This is precisely why authoritarian regimes persecute artists. As Creative Interruptions' authors acknowledge, the creation of art can be an elite activity, traditionally requiring time and money for study and creation, an individualistic investment in the concept of the lone artistic genius and immense social capital (necessarily bounded by privileges of sex, race, class and location) to 'succeed'.

This restructuring of the creative sector also involves radical activation around class and privilege. It is time to do away with the traditions of unpaid internships, work done for free, exploited labour, crony networks, the ignoring of childcare and travel costs and other forms of complacency around artists' earnings and the necessity of making a living. I personally 


\section{On radical transformation}

believe in organisations and institutions, and I believe that artists of talent should be financially enabled to have long careers and create substantial lifelong bodies of work. Without concrete support, the arts - whether film, theatre, visual art, dance or literature - will remain an option only for those who are already rich.

In Chapter 5, 'Creatively connecting civil rights: co-creation, theatre and collaboration for social transformation in Belfast', the authors dismantle hegemonic definitions of what constitutes an artist and what constitutes 'successful' art. They bring the periphery to the centre, the immobilised and silenced into sound and motion. Using community theatre as their example - but really extending theoretically towards all forms of artistic collaboration, creation and distribution or display - they make visible the narratives and forms created by migrants and ethnic minorities. In doing so, they reveal nations' and societies' historiographies of 'great art' to be a sham. The decision about who is an artist and what is art is political, is hegemonic. It is about reinforcing power structures and justifying inequality. The issue of who gets to speak, who is given power and who is recognised as rightfully taking up space with authority is not confined to some rarefied 'art world' but informed by centuries-long histories of oppression, exploitation and prejudice which - as with colonisation and slavery - often span dozens of countries. Unless they make an honest and humbling reckoning with its history, the arts will never move into the future with authenticity.

However, this has not stopped a critical mass of creators from communities and cohorts who are not 'supposed' to be artists, and have not been recognised as artists, from making art. And it has not stopped those from heavily oppressed communities, like the citizens of occupied Palestine, from making art which directly speaks to, pulls at and confronts their oppression.

Creative Interruptions marries creativity and cultural theory, politicised histories and creative futures, academia and politics, art and activism. Its many contributing voices all ultimately identify creativity as a significant channel for social change, for widened perspectives and for the revelation and illumination of unheard, ignored and disenfranchised voices. 
These are difficult conversations to have, but they are necessary and long overdue. A radical revival of liberation movements within all the arts is necessary for the change that must be brought into being. The alternative is a constant repetition of shallow initiatives and patronising platitudes that people of colour in the arts and media have experienced too many times. I am tired of attending panel discussions on diversity and inclusion and listening to the excuses and whining of liberal white gatekeepers who never question their own unconscious racism, entitlement, ignorance and privilege.

Creative Interruptions rejects the idea that art is somehow above society. Indeed, it acknowledges creative thinking as a necessary tool in the achievement of social justice. The voices in the book do not beg to be included by 'the mainstream'; instead they insist upon the valuable wisdom that marginalisation bestows.

This book is part of the journey towards a radical transformation. I do believe that crisis and opportunity go hand in hand, and that rupture opens a space for self-reinvention. In the closing chapter, on Punjab, the authors look forwards not to a recreating but (tellingly) 'Re-curating a literary utopia'. This makes me think of the 'radical re-hangs' some major museums are now doing: going down into their basement of hidden artworks, images and stories, long left ignored in the dark, and looking properly - perhaps for the first time - at the ones created by women, non-whites, foreigners, immigrants, those who have been abused, marginalised, (mis-)represented but not heard from. It means a radical new approach: seeing the stuff that was previously shoved out of sight and talked down, but which existed nonetheless. It means taking away all the old canonical stories, looking at the full breadth of what we have in the world and making an inspired re-hang to tell different narratives.

Creative Interruptions is a chronicle of the struggle and a celebration of diverse victories and of creativity forged in suffering. It privileges collaboration, dialogue, productive activism, self-image-making and interventions as powerful methods of social and artistic change in an increasingly dark and cold world. It also reclaims marginalisation as a vantage point, a clear space for observation, from which we speak our truth. 